\title{
Clinical Study \\ Transperitoneal Subcostal Access for Urologic Laparoscopy: Experience of a Large Chinese Center
}

\author{
Lei Zhang, Dong Fang, Xuesong Li, Lin Yao, Gengyan Xiong, Zhisong He, and Liqun Zhou \\ Department of Urology, Peking University First Hospital, Institute of Urology, Peking University, National Urological Cancer Center, \\ Beijing 100034, China
}

Correspondence should be addressed to Xuesong Li; pineneedle@sina.com and Liqun Zhou; zhoulqmail@sina.com

Received 5 August 2016; Revised 5 October 2016; Accepted 24 October 2016

Academic Editor: Nevzat C. Şener

Copyright (C) 2016 Lei Zhang et al. This is an open access article distributed under the Creative Commons Attribution License, which permits unrestricted use, distribution, and reproduction in any medium, provided the original work is properly cited.

Objective. To present our experience of using transperitoneal subcostal access, Palmer's point $(3 \mathrm{~cm}$ below the left costal margin in the midclavicular line), and its right corresponding site, in urologic laparoscopy. Methods. We used Palmer's point and the right corresponding site for initial access in 302 urologic surgeries (62 cases with prior surgeries). The record of these cases was reviewed. Results. Success rate of initial access is $99.4 \%$, and complication rate of puncturing is only $3.4 \%$ with no serious complication. In the cases with prior surgeries, there were only two cases with access complication on the right side (minor laceration of liver). For people with BMI more than $30 \mathrm{~kg} / \mathrm{m}^{2}$ (12,3.9\%), the success rate was also 100 percent. Conclusions. Palmer's point and the corresponding right location are feasible, effective, and safe for initial access in urologic laparoscopic surgeries. This entry technique should be used routinely in urologic laparoscopic surgeries.

\section{Introduction}

The establishment of pneumoperitoneum is considered to be a dangerous step in laparoscopic surgery. Potential complications include injury of vessels, the gastrointestinal tract, and the urinary tract as well as gas embolism. Approximately $50 \%$ of all laparoscopic complications have been attributed to the entry technique [1]. The risk is higher for patients with a history of abdominal surgery because of adhesion.

In 1974, Palmer [2] first described an abdominal entry point for patients with prior surgery located $3 \mathrm{~cm}$ below the left costal margin in the midclavicular line. This entry point, now known as Palmer's point, is noted to produce good results when establishing pneumoperitoneum [3-10]. However, all of the published guidelines have restricted their recommendations for Palmer's point to patients in whom adhesions are suspected $[11,12]$. The value of Palmer's point may therefore be underestimated.

There are only a few published studies concerning the use of Palmer's point and the corresponding right point as the initial access sites in laparoscopic surgeries [3-10]. In these studies, the points were primarily used for gynecologic operations $[3-6,8,10]$; only two articles describe urological surgeries [7,9]. No studies have described the use of Palmer's point as the initial access site for Chinese patients.

We used transperitoneal subcostal access (Palmer's point and its corresponding right point) for establishing pneumoperitoneum in 302 urologic laparoscopic surgeries. To the best of our knowledge, this study is the first report of transperitoneal subcostal access in urologic laparoscopy for Chinese patients.

\section{Materials and Methods}

A retrospective review of studies describing laparoscopic surgeries using Palmer's point or the corresponding right point to establish pneumoperitoneum between April 2009 and September 2013 was conducted. Palmer's point or the corresponding right point was used for left- or right-sided operations, respectively. A total of 302 cases were identified (Table 1), including radical nephrectomy $(n=131 ; 43.4 \%)$, nephroureterectomy ( $n=78 ; 25.8 \%$ ), partial nephrectomy $(n=32 ; 10.6 \%)$, pyeloplasty $(n=29 ; 9.6 \%)$, simple nephrectomy $(n=12 ; 4.0 \%)$, adrenalectomy $(n=10$; $3.3 \%)$, renal cyst decortication $(n=6 ; 2.0 \%)$, and segmental ureterectomy $(n=4 ; 1.3 \%)$. The patient demographics 


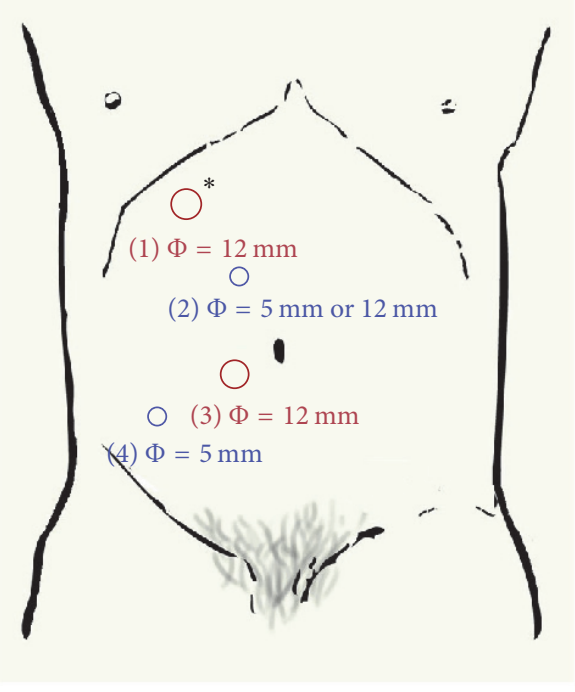

(a)

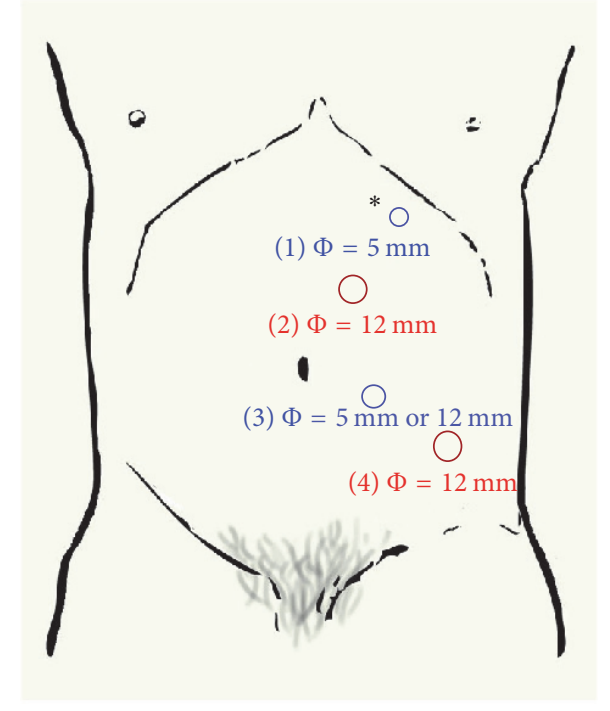

(b)

FIgURE 1: Transperitoneal subcostal access for urologic laparoscopy. (a) Trocar site for right-sided operations. (b) Trocar site for left-sided operations. * Primary insertion site.

TABle 1: Patient demographics.

\begin{tabular}{lc}
\hline Sex, $n(\%)$ & $142(47.0 \%)$ \\
Women (\%) & $160(53.0 \%)$ \\
Men $(\%)$ & \\
Age, years & $55.01 \pm 16.90$ \\
Mean \pm SD & $57,16-88$ \\
Median, range & \\
BMI, kg/m ${ }^{2}$ & $24.01 \pm 3.16$ \\
Mean \pm SD & $23.99,16.53-35.22$ \\
Median, range & \\
Side, $n(\%)$ & $136(45.0 \%)$ \\
Right & $164(54.3 \%)$ \\
Left & $2(0.7 \%)$ \\
Bilateral & \\
Surgery history, $n(\%)$ & $62(20.5 \%)$ \\
Presence & $240(49.5 \%)$ \\
Absence & \\
Duration of follow-up, months & $28.0 \pm 11.59$ \\
Mean \pm SD & $28.0,7-60$ \\
Median, range &
\end{tabular}

are shown in Table 1 . The average age was $55.01 \pm 16.90$ years (range, 16 to 88 years). The average BMI was $24.01 \pm$ $3.16 \mathrm{~kg} / \mathrm{m}^{2}$ (range, $16.53-35.22 \mathrm{~kg} / \mathrm{m}^{2}$ ), 12 patients were more than $30 \mathrm{~kg} / \mathrm{m}^{2}, 22$ patients were less than $20 \mathrm{~kg} / \mathrm{m}^{2}$, and 268 patients were between $20 \mathrm{~kg} / \mathrm{m}^{2}$ and $30 \mathrm{~kg} / \mathrm{m}^{2}$. Fortysix patients were ASA I, 227 patients were ASA II, and 29 patients were ASA III. Sixty-two (20.5\%) cases were with prior abdominal surgery history. Previous surgical history and patients habitus were not contraindications to blind insertion of the Veress needle.

Under general anesthesia, the patient is placed in the lateral recumbent position (45 degrees from horizontal) with the lesion side up. For the left-sided operation, a $1 \mathrm{~cm}$ horizontal incision was made $3 \mathrm{~cm}$ below the left costal margin in the midclavicular line (Palmer's point) (Figure 1(b)). The Veress needle was held similar to a dart to perpendicularly penetrate the skin using the dominant hand. The procedure of penetrating the skin should be slow, and the breakthrough should be felt two or three times before entry into the cavity. A saline drop test was used to confirm the entry into the peritoneal cavity. Carbon dioxide was insufflated into the cavity at a low flow rate, and the intra-abdominal pressure was shown on the monitor. The initial pressure was usually 4$5 \mathrm{mmHg}$. If the pressure increased slowly from it to $14 \mathrm{mmHg}$, pneumoperitoneum was successfully established. Otherwise, the carbon dioxide may not enter into the cavity or the flow was obstructed, and the needle should be removed. A semiopen entry was used after attempting the procedure more than three times. Once pneumoperitoneum was established, a trocar $(10 \mathrm{~mm})$ was inserted through the initial puncture site. A $30^{\circ}$ laparoscope was inserted through the trocar to identify whether the viscera or vessels were injured. Other trocars were inserted using the aid of the laparoscope. For right-sided operations, the primary puncture site was the corresponding site of Palmer's point, $3 \mathrm{~cm}$ below the right costal margin in the midclavicular line. The subsequent procedure was commensurate with that of the left side.

The complications relative to the blind insertion of the Veress needle were recorded, including minor and major complications. The minor complications were defined as those that did not affect the length of hospital stay. The major complications included those leading to death, those 
TABLE 2: Review of Palmer's point or the corresponding right point for initial access in laparoscopic surgeries.

\begin{tabular}{lccccc}
\hline Reference & Year & Number of cases & $\begin{array}{c}\text { Success rate of } \\
\text { puncturing }\end{array}$ & $\begin{array}{c}\text { Rate of } \\
\text { complication }\end{array}$ & $\begin{array}{c}\text { Rate of conversion } \\
\text { to open operation }\end{array}$ \\
\hline Childers et al. [3] & 1993 & 41 & $97.6 \%, 40$ & $2.4 \%$ & $2.4 \%$ \\
Chang et al. [4] & 1994 & 17 & $100 \%$ & 0 & 0 \\
Parker et al. [5] & 1999 & 17 & $100 \%$ & 0 \\
Patsner [6] & 1999 & 90 & $100 \%$ & $2.2 \%$ & 0 \\
Chung et al. [7] & 2003 & 622 & $93 \%$ & $8 \%$ (minor & 0 \\
Tulikangas et al. [8] & 2003 & 267 & $98.5 \%, 263$ & $1.1 \%$ & 0 \\
Tüfek et al. [9] & 2010 & 147 & $100 \%$ & 0 & 0 \\
Granata et al. [10] & 2010 & 136 & $98.5 \%$ & 0 & 0 \\
\hline
\end{tabular}

requiring conversion to an open operation, and those requiring prolonged hospitalization.

\section{Results and Discussion}

The layout of the trocar is shown in Figures 1(a) and 1(b) for right- and left-sided operations, respectively. Of the 302 transperitoneal laparoscopic operations, the Veress needle was successfully inserted in 299 cases (99.0\%). Three failed cases were not associated with prior abdominal surgeries, obesity, or thinness. No open operation was performed because of puncturing complications. No serious complications occurred, such as perforation of vessels or the gastrointestinal tract. Minor complications occurred in ten cases (3.3\%): five cases demonstrated injury of Glisson's capsule, three cases demonstrated injury of the omentum, and two cases demonstrated injury of the falciform ligament. After a simple hemostasis, the operations continued, and there were no sequelae. In all 62 cases with previous surgery, adhesions of different degrees were detected. However, the Veress needle insertions were successful in all of these cases, and there were only four cases with access complications (minor injury of Glisson's capsule). For individuals with BMIs $>30 \mathrm{~kg} / \mathrm{m}^{2}$ $(n=12 ; 3.9 \%)$ and $<20 \mathrm{~kg} / \mathrm{m}^{2}(n=22 ; 7.3 \%)$, the success rate was 100 percent. After establishing pneumoperitoneum, the initial access site could be used for the insertion of the laparoscope and other instruments. No incision infection or pneumothorax was found postoperatively. None of the patients developed an incision hernia at the trocar site after a 28-month follow-up.

Entry into the peritoneal cavity and the establishment of pneumoperitoneum constitute the most dangerous steps in laparoscopic surgery; approximately $50 \%$ of all complications occur during these steps [1]. Several complications, such as gastrointestinal tract perforation and massive hemorrhage, could result in fatal outcomes. Recently, many methods have been proposed for minimizing injuries, especially in patients with prior surgeries and intraperitoneal adhesions. There is no consensus on which approach is the safest [13].

The periumbilical region is the traditional site of initial access in laparoscopic surgery because the abdominal wall is thin, which facilitates insertion of the needle. However, there are several problems concerning this access technique. First, the periumbilical region is always unclean and more susceptible to infection. There are several great vessels under the umbilicus. When instruments are inserted in the periumbilical region, the risk of major vessel injury is between 0.5 and 6.4 per 100 laparoscopies [14-16], which could be lethal. Furthermore, the patient's weight has a considerable effect on the periumbilical abdominal wall thickness. The strength required for inserting the Veress needle is markedly different between thin and obese patients. Moreover, for patients with prior abdominal surgery, there is a two-fold increased risk of access complication at the umbilical site [17]. Thus, the use of this technique is restricted, especially for patients with prior surgery.

In 1974, Palmer first described a puncture site, now known as Palmer's point that could be used in patients with prior surgeries [2]. Previous studies have shown satisfactory results for establishing pneumoperitoneum at Palmer's point or the corresponding right point (Table 2). The success rate for establishing pneumoperitoneum at these points was 93$100 \%$, although a significant portion of the patients had prior surgeries. However, few studies have described the use of Palmer's point for establishing pneumoperitoneum, and no studies have been performed on Asian patients. This is likely because all the guidelines have restricted their recommendations for using Palmer's point to cases in which abdominal adhesions are suspected. Moreover, the majority of laparoscopic operations have been performed by gynecologic surgeons for the treatment of pelvic lesions. Periumbilical insufflation is traditionally used by gynecologists, and there are no prospective studies that document the safest entry technique. Hence, the surgeon's choice is usually based on this practice.

Based on the satisfactory results achieved with this technique, we believe that the value of Palmer's point for Western patients is underestimated. However, the habitus differs between Western and Chinese patients. The value of Palmer's point and its corresponding point as the initial access points for Chinese people is unknown in urologic surgeries of the upper urinary tract. We expanded the use of Palmer's point without restriction for patients with suspected adhesions. 
Finally, we used Palmer's point and the corresponding right point for primary needle insertion in 302 transperitoneal laparoscopic operations. The results were compelling, with a success rate of $99.0 \%$, a complication rate of only $3.3 \%$, and no serious complications. However, we should note that Palmer's point corresponding site on the right side is not as safe as Palmer's point because there are liver, gallbladder, duodenum, and vena cava under the right site. It is reasonable to move the right entrance site about $2 \mathrm{~cm}$ below comparing to the left side.

The use of Palmer's point or the corresponding right point for establishing pneumoperitoneum has several advantages. First, because the peritoneum is fixed and braced anteriorly by the arch rib, inserting the Veress needle requires less effort; thus, abdominal traction (e.g., using two towel clips) is unnecessary. Second, there is less subcutaneous fat at Palmer's point, even in obese patients [18]. Thus, inserting the needle is easy and is unaffected by the shape of the patient. Third, with the aid of gravity, the viscera fall away from Palmer's point. There are no major vessels at this site. Inserting the Veress needle in this area is theoretically safe. Additionally, the average distance from Palmer's point to the aorta is $11.3 \pm$ $0.2 \mathrm{~cm}$ [18]. When inserting the Veress needle caudally at $45^{\circ}$, the distance is extended to $16.6 \pm 0.2 \mathrm{~cm}$ [18]. Although the length of the Veress needle is usually $12 \mathrm{~cm}$, the risk of aortic injury approaches zero. Third, adhesion is rare in these areas, even in patients with prior surgeries.

Based on our experience, transperitoneal subcostal access is feasible, effective, and safe in urologic laparoscopic surgeries. Consistent with our opinion, Chung et al. [7] have proposed that this access technique can be routinely used in transperitoneal laparoscopic surgery, especially that involving the upper urinary tract, and should not be reserved for patients with suspected adhesions. Additionally, Tüfek et al. [9] indicated that Palmer's point Veress needle access was a safe and effective method for establishing pneumoperitoneum in patients subjected to robotic and standard laparoscopic radical prostatectomy.

Our experience showed that the success rate for establishing pneumoperitoneum was $100 \%$ in patients with BMIs $>30 \mathrm{~kg} / \mathrm{m}^{2}$ and $<20 \mathrm{~kg} / \mathrm{m}^{2}$, which indicated that the use of transperitoneal subcostal access was unaffected by the patient's shape. Approximately 50\% of the complications were attributed to injury of Glisson's capsule in this series. We should apply caution when using these locations as the initial access point for patients with large livers. Under these circumstances, the puncture site should be moved downward to avoid the margin of the liver.

This study had several limitations. First, it was a retrospective study conducted in a single institution with selection bias. Second, all the puncturing procedures were performed by a single surgeon with considerable experience. These compelling results may not be reproduced by a surgeon with less experience. With increased experience, the use of this technique could produce satisfactory outcomes. Third, because of the retrospective nature of this study, it is still uncertain whether transperitoneal subcostal access is better than periumbilical access for initial access in laparoscopic surgeries. Prospective randomized controlled trials are warranted.

\section{Conclusions}

In summary, our initial experience demonstrated that Palmer's point or the corresponding right point was feasible, effective, and safe for initial access in urologic laparoscopic surgeries. These sites should be used routinely for establishing pneumoperitoneum in urologic laparoscopic surgeries and should not be limited to patients with suspected adhesions.

\section{Competing Interests}

The authors declare that they have no competing interests.

\section{Authors' Contributions}

Lei Zhang and Dong Fang contributed equally to this work.

\section{References}

[1] F. W. Jansen, W. Kolkman, E. A. Bakkum, C. D. De Kroon, T. C. M. Trimbos-Kemper, and J. B. Trimbos, "Complications of laparoscopy: an inquiry about closed-versus open-entry technique," American Journal of Obstetrics and Gynecology, vol. 190, no. 3, pp. 634-638, 2004.

[2] R. Palmer, "Safety in laparoscopy," Journal of Reproductive Medicine, vol. 13, no. 1, pp. 1-5, 1974.

[3] J. M. Childers, P. R. Brzechffa, and E. A. Surwit, "Laparoscopy using the left upper quadrant as the primary trocar site," Gynecologic Oncology, vol. 50, no. 2, pp. 221-225, 1993.

[4] F. H. Chang, C. L. Lee, and Y. K. Soon, "Use of Palmer's point for insertion of the operative laparoscope in patients with severe pelvic adhesions: experience of seventeen cases," The Journal of the American Association of Gynecologic Laparoscopists, vol. 1, no. 2, 1994.

[5] J. Parker, G. Reid, and F. Wong, "Microlaparoscopic left upper quadrant entry in patients at high risk of periumbilical adhesions," Australian and New Zealand Journal of Obstetrics and Gynaecology, vol. 39, no. 1, pp. 88-92, 1999.

[6] B. Patsner, "Laparoscopy using the left upper quadrant approach," Journal of the American Association of Gynecologic Laparoscopists, vol. 6, no. 3, pp. 323-325, 1999.

[7] H.-J. Chung, M. V. Meng, H. M. Abrahams, and M. L. Stoller, "Upper quadrant access for urologic laparoscopy," Urology, vol. 62, no. 6, pp. 1117-1119, 2003.

[8] P. K. Tulikangas, D. S. Robinson, and T. Falcone, "Left upper quadrant cannula insertion," Fertility and Sterility, vol. 79, no. 2, pp. 411-412, 2003.

[9] I. Tüfek, H. Akpinar, C. Sevinç, and A. R. Kural, "Primary left upper quadrant (Palmer's point) access for laparoscopic radical prostatectomy," Urology Journal, vol. 7, no. 3, pp. 152-156, 2010.

[10] M. Granata, I. Tsimpanakos, F. Moeity, and A. Magos, "Are we underutilizing Palmer's point entry in gynecologic laparoscopy?" Fertility and Sterility, vol. 94, no. 7, pp. 2716-2719, 2010.

[11] R. E. Richardson and C. J. G. Sutton, "Complications of first entry: a prospective laparoscopy audit," Gynaecological Endoscopy, vol. 8, no. 6, pp. 327-334, 1999. 
[12] Royal College of Obstetricians and Gynaecologists, Preventing entry-related gynaecological laparoscopic injuries: Green-top Guideline No. 49, London, UK, Royal College of Obstetricians and Gynaecologists, 2008.

[13] T. L. Merlin, J. E. Hiller, G. J. Maddern, G. G. Jamieson, A. R. Brown, and A. Kolbe, "Systematic review of the safety and effectiveness of methods used to establish pneumoperitoneum in laparoscopic surgery," British Journal of Surgery, vol. 90, no. 6, pp. 668-679, 2003.

[14] M. Mintz, "Risks and prophylaxis in laparoscopy: a survey of 100,000 cases," Journal of Reproductive Medicine for the Obstetrician and Gynecologist, vol. 18, no. 5, pp. 269-272, 1977.

[15] M. H. Saidi, T. G. Vancaillie, A. J. White, R. K. Sadler, B. D. Akright, and S. A. Farhart, "Complications of major operative laparoscopy: a review of 452 cases," Journal of Reproductive Medicine for the Obstetrician and Gynecologist, vol. 41, no. 7, pp. 471-476, 1996.

[16] G. Champault, F. Cazacu, and N. Taffinder, "Serious trocar accidents in laparoscopic surgery: a French survey of 103,852 operations," Surgical Laparoscopy \& Endoscopy, vol. 6, no. 5, pp. 367-370, 1996.

[17] A. I. Brill, F. Nezhat, C. H. Nezhat, and C. Nezhat, "The incidence of adhesions after prior laparotomy: a laparoscopic appraisal," Obstetrics and Gynecology, vol. 85, no. 2, pp. 269-272, 1995.

[18] N. M. Giannios, V. Gulani, K. Rohlck, R. L. Flyckt, S. J. Weil, and W. W. Hurd, "Left upper quadrant laparoscopic placement: effects of insertion angle and body mass index on distance to posterior peritoneum by magnetic resonance imaging," American Journal of Obstetrics \& Gynecology, vol. 201, no. 5, pp. 522.e1-522.e5, 2009. 


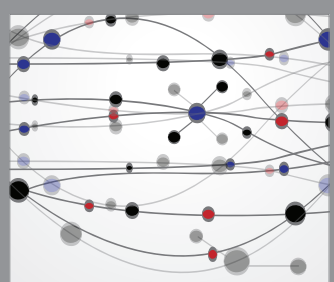

The Scientific World Journal
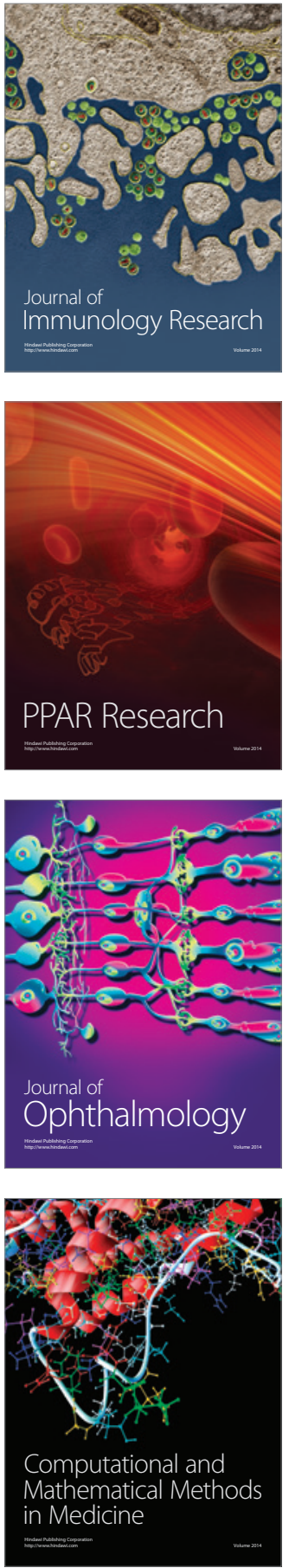

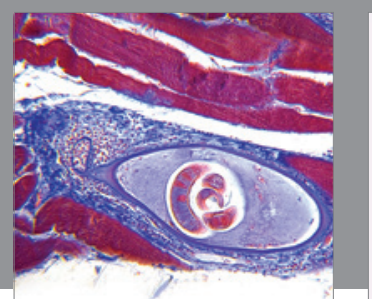

Gastroenterology Research and Practice

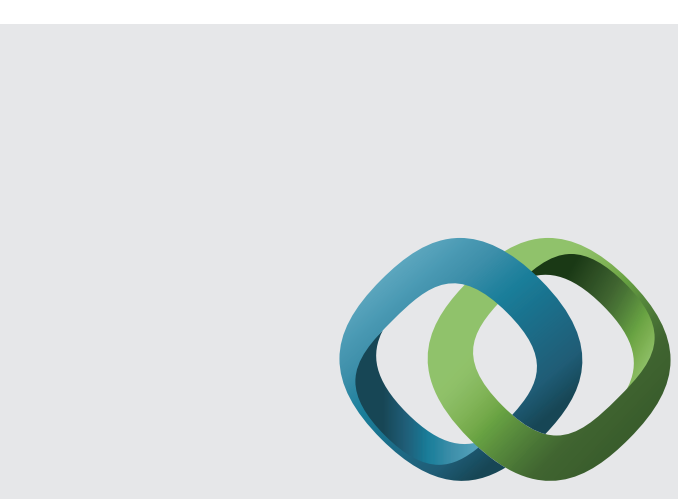

\section{Hindawi}

Submit your manuscripts at

http://www.hindawi.com
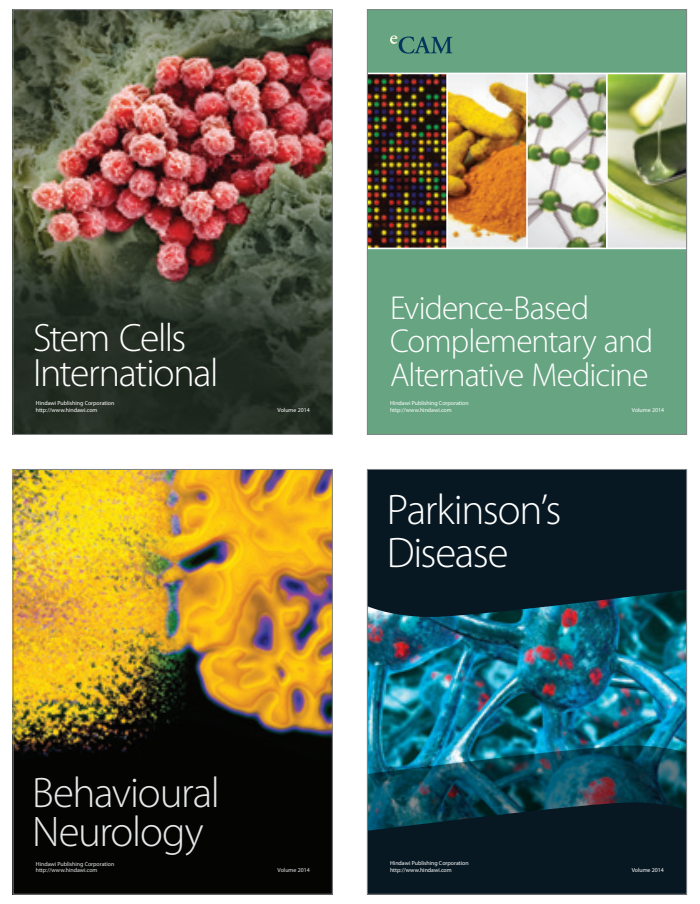
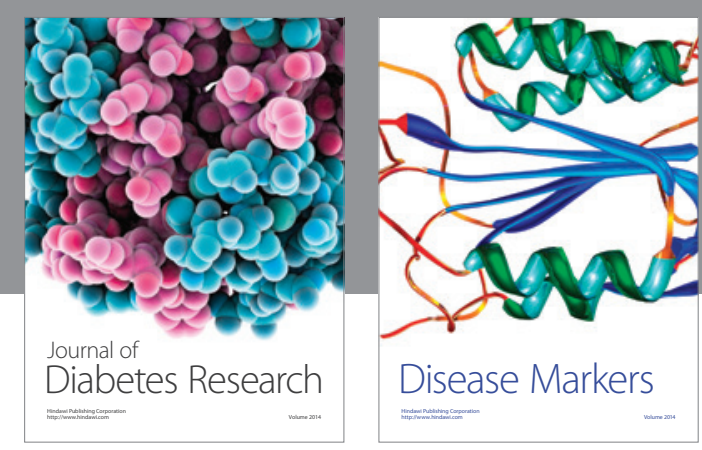

Disease Markers
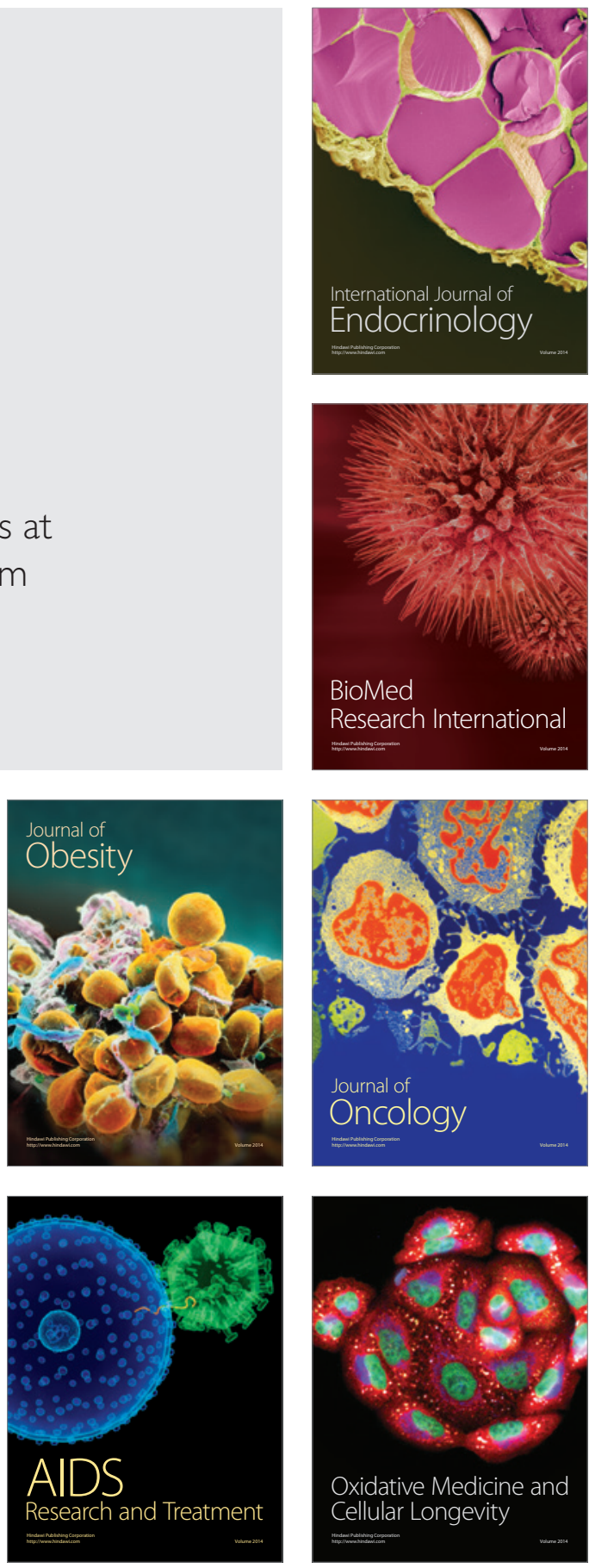